\title{
Mast cells are associated with exacerbations and eosinophilia in children with severe asthma
}

\author{
Guillaume Lezmi ${ }^{1,2}$, Louise Galmiche-Rolland ${ }^{2,3}$, Sabine Rioux ${ }^{1}$, \\ Francis Jaubert ${ }^{2,3}$, Isabelle Tillie-Leblond ${ }^{4,5,+}$, Pierre Scheinmann ${ }^{1,2}$, \\ Philippe Gosset ${ }^{4,5,6,7,8}$ and Jacques de Blic ${ }^{1,2}$
}

Affiliations: 'Service de Pneumologie et d'Allergologie Pédiatriques, AP-HP, Hôpital Necker-Enfants Malades, Paris, France. ${ }^{2}$ Université Paris Descartes, Paris, France. ${ }^{3}$ Service d'Anatomopathologie, AP-HP, Hôpital Universitaire Necker-Enfants Malades, Paris, France. ${ }^{4}$ Université Lille Nord de France, Lille, France. ${ }^{5}$ Centre d'Infection et d'Immunité de Lille, Institut Pasteur de Lille, Lille, France. ${ }^{6}$ Centre National de la Recherche Scientifique, UMR 8204, Lille, France. ${ }^{7}$ Institut National de la Santé et de la Recherche Médicale, U1019, Lille, France. ${ }^{8}$ Institut Fédératif de la Recherche 142, Lille, France.

Correspondence: Jacques de Blic, Service de Pneumologie et d'Allergologie Pédiatriques, Hôpital Necker Enfants-Malades, 149 rue de Sèvres, 75015 Paris, France. E-mail: j.debliclanck.aphp.fr

ABSTRACT The role of mast cells in the pathogenesis of childhood asthma is poorly understood. We aimed to estimate the implication of airway mucosal mast cells in severe asthma and their relationship with clinical, functional, inflammatory and remodelling parameters.

Bronchial biopsies were performed in 36 children (5-18 years) with severe asthma: 24 had frequent severe exacerbations and/or daily symptoms in the previous year (symptomatic group), and 12 had few symptoms and a persistent obstructive pattern (paucisymptomatic group). Nine children without asthma were included as control subjects. We assessed mast cells in the submucosa and airway smooth muscle using c-kit antibodies and in the entire biopsy area using Giemsa.

The number of submucosal mast cells was higher in the symptomatic group than in the paucisymptomatic group $(\mathrm{p}=0.02)$. The number of submucosal mast cells correlated with the number of severe exacerbations ( $\mathrm{p}=0.02, \mathrm{r}=0.37$ ). There were positive correlations between the number of submucosal mast cells $(p<0.01, r=0.44)$, airway smooth muscle mast cells $(p=0.02, r=0.40)$, mast cells stained by Giemsa $(\mathrm{p}<0.01, \mathrm{r}=0.44)$ and submucosal eosinophils.

Mast cells are associated with severe exacerbations and submucosal eosinophilic inflammation in children with severe asthma.

@ERSpublications

Submucosal mast cells are associated with exacerbations and submucosal eosinophilia in children with severe asthma http://ow.ly/uwly302J5mE

This article has supplementary material available from erj.ersjournals.com

Received: May 112016 | Accepted after revision: July 262016 | First published online: Oct 062016

Conflict of interest: Disclosures can be found alongside this article at erj.ersjournals.com

Copyright OERS 2016 


\section{Introduction}

Studies in adults with asthma have provided evidence that mast cells (MCs) are involved in the pathogenesis of asthma [1-11]. In adults with asthma, MCs are distributed in large and small airways $[2,3]$ and within the epithelium [4-6], the submucosa [5-7] and the submucosal glands [2]. The presence of MCs in airway smooth muscle (ASM) also appears to be a key feature of asthma pathogenesis $[4,8,9]$. MCs are the most prominent inflammatory cells in the ASM bundles of adults with asthma, whereas only a few MCs are found in the ASM bundles of healthy controls or in patients with eosinophilic bronchitis [8-10]. MCs in the ASM of subjects with asthma are often degranulated, suggesting that they are activated $[2,8]$. Finally, ASM MC numbers have been shown to be associated with clinical and functional parameters, and with some features of remodelling in adults with asthma $[2,4,5,9-11]$.

The involvement of MCs in the pathogenesis of asthma in children is less well described. The same number of MCs are present in the subepithelial mucosa of children with wheezing or mild-to-severe asthma as in control subjects [12-15]. MCs are also detected with the same frequency in the ASM of preschool-age children who wheeze and schoolchildren with severe asthma as in controls [16, 17]. The association between MCs and symptoms, lung functions, remodelling or inflammation in children with severe asthma thus remains poorly described.

In the present study, we aimed to analyse whether the number of MCs correlated with clinical, functional, inflammatory and remodelling parameters. We hypothesised that MCs are present in the ASM of children with severe asthma, and that ASM MCs are related to the clinical presentation.

\section{Materials and methods}

This study was approved by the institutional review board of Necker Hospital. Written informed consent was obtained from the parents. Some children have been included in previous studies $[18,19]$.

\section{Subjects}

Children aged 5-18 years with difficult-to-treat asthma referred to Necker hospital were followed every 2-3 months for at least 12 months before inclusion. At each visit, symptoms, adherence to treatment and inhalation methods were recorded and lung functions tests were performed. Those with persistent symptoms and/or bronchial obstruction under high doses of inhaled corticosteroids (ICS), despite good adherence and inhalation technique, underwent further investigations (details are available in the supplementary material). Children with severe asthma were included. Severe asthma was defined according to the American Thoracic Society (ATS) workshop as requiring treatment with high-dose ICS and the presence of at least two of the following minor criteria: the need for a daily long-lasting $\beta 2$-agonist or leukotriene antagonist treatment, short-acting $\beta 2$-agonist use on a daily or near-daily basis, persistent airway obstruction (post-bronchodilator forced expiratory volume in $1 \mathrm{~s}$ (FEV1) $<80 \%$ predicted), one or more emergency care asthma visits, or three or more oral steroid bursts per year [20]. Subjects with severe asthma were divided a priori into two groups based on their symptom patterns and lung function during the previous 12 months, as previously described $[18,19]$. Symptomatic children (S group) were those with more than three severe exacerbations and/or daily symptoms requiring the use of a short-acting $\beta 2$-agonist more than three times per week, with or without airway obstruction. Paucisymptomatic children (PS group) were those with a persistent obstructive pattern (see "Spirometry") and three severe exacerbations or less who exhibited daily symptoms requiring the use of a short-acting $\beta 2$-agonist three times per week or less. The recent ATS/European Respiratory Society (ERS) guidelines on severe asthma were published after the end of patient inclusion, and define frequent severe exacerbations as those requiring two or more bursts of systemic corticosteroids in the previous year [21]. We therefore performed additional analyses using two as the cut-off value for the number of exacerbations. Children diagnosed with conditions other than severe asthma were excluded and comorbidities and contributory factors were treated (details are available in the supplementary material) [20].

Children with no history of asthma, no need for inhaled or oral steroids during the previous 6 months, and requiring a flexible bronchoscopy with bronchoalveolar lavage (BAL) were included as control subjects.

Atopy was defined as a positive standard skin prick test (SPT) and/or specific IgE levels for current allergens (details are available in the supplementary material).

\section{Spirometry}

Spirometry was performed as previously described $[18,19]$. Paucisymptomatic patients with a non-reversible airflow limitation (post-bronchodilator $\mathrm{FEV}_{1}<80 \%$ predicted with an $\mathrm{FEV} 1$ to forced vital capacity (FVC) ratio $<80$ and a $<12 \%$ increase in $\mathrm{FEV} 1$ ) underwent a second spirometry after 2 weeks of a $2 \mathrm{mg} \cdot \mathrm{kg}^{-1} \cdot \mathrm{day}^{-1}$ course of oral prednisone. A persistent obstructive pattern was defined as a post-bronchodilator FEV $1<80 \%$ after the steroid course [22]. 


\section{Bronchoscopy}

Flexible bronchoscopy was performed at least 4-6 weeks after the end of a systemic corticosteroid course, as previously described $[18,19]$. Biopsy samples were taken from the segmental bronchi of the right or left lower lobe. In children with a persistent obstructive pattern, bronchoscopy was performed 4-6 weeks after the course of steroids.

\section{Tissue processing}

Four to six biopsy samples were taken. Bronchial biopsies with an altered structure were not used. The minimum size of the analysed section was $0.1 \mathrm{~mm}^{2}$, (range $0.1-1.5 \mathrm{~mm}^{2}$ ). The best sample was used for analysis. Sections were stained with Giemsa and the number of eosinophils, neutrophils and lymphocytes was assessed in the submucosa and expressed as cell number per square millimetre. MCs were stained with monoclonal mouse anti-human c-kit (CD117, clone A4502, diluted 1/400; Dako, Glostrup, Denmark) and Giemsa. The number of MCs stained with c-kit was assessed 1) in the submucosa and reported as cell number per square millimetre of submucosa and 2) in the ASM bundles and reported as cell number per square millimetre of ASM. The number of MCs stained with Giemsa was assessed in the total biopsy sample area and reported as cell number per square millimetre of biopsy sample area.

Epithelial integrity, reticular basement membrane (RBM) thickness $(\mu \mathrm{m})$, the percentage of the submucosa occupied by mucus glands and ASM, and angiogenesis were assessed as described elsewhere [23].

Parameters were evaluated by two independent observers blind to the study cohort. The results are expressed as the median of all measurements obtained for each patient. The mean biopsy sample area was $0.59 \mathrm{~mm}^{2}$ (range $0.1-1.5 \mathrm{~mm}^{2}$ ). For all parameters, the coefficient of variation for two sections from the same biopsy was $15 \%$, and that between biopsies from the same patient was $18 \%$. The inter-observer reproducibility was $>85 \%$.

\section{Statistical analysis}

Insufficient data were available to perform power calculations. Data are expressed as the median (interquartile range). Differences between groups were assessed using the Mann-Whitney test. Correlation analyses were performed using Spearman's rank correlation analysis. A $\mathrm{p}<0.05$ was considered to be significant. Data were analysed using GraphPad Prism version 5.03 (GraphPad Software, Inc., San Diego, CA, USA).

\section{Results}

\section{Subjects}

The general characteristics of patients with asthma and control subjects are shown in table 1 . Thirty-six children with severe asthma and nine control subjects were included. Children in the control group were suspected of sarcoidosis and biopsies were performed to assess granulomatous inflammation. The diagnosis of sarcoidosis was only confirmed in three patients. We found no evidence of a granulomatous inflammation in the other six patients, who were given a final diagnosis of inflammatory (non-sarcoidosis) uveitis. The demographics were similar between children with severe asthma and control subjects. Among

\section{TABLE 1 Clinical characteristics of patients}

\begin{tabular}{lccc} 
& Control subjects & \multicolumn{2}{c}{ Severe asthma } \\
\cline { 3 - 4 } & & Symptomatic & Paucisymptomatic \\
\hline Number & 9 & 24 & 12 \\
Age years & $9.1(7.7-12.8)$ & $10.6(8.9-12.1)$ & $12.9(9.9-14)$ \\
Sex (male/female) & $4 / 5$ & $15 / 9$ & $9 / 3$ \\
Atopic $\mathbf{n}(\%)$ & NA & $16(67)$ & $11(92)$ \\
Sensitisation to aeroallergens $\mathbf{n}(\%)$ & NA & $12(50)$ & $9(75)$ \\
Sensitisation to food allergens $\mathbf{n}(\%)$ & NA & $6(25)$ & $2(17)$ \\
Age at diagnosis years & NA & $1(0.9-2)$ & $1(0.6-1.9)$ \\
Regular inhaled steroids & NA & 24 & 12 \\
Inhaled steroids $\mu$ g per day eq BDP & NA & $1000(800-1150)$ & $1000(900-1250)$ \\
Exacerbations in the past 12 months & NA & $6(5-10)$ & $0.5(0-2.3)^{\#}$ \\
FEV $(\%$ predicted) & NA & $79(74-91.5)$ & $71.5(66.8-74.8)^{\pi}$ \\
\hline
\end{tabular}

Data are presented as median (interquartile range), unless otherwise stated. Eq BDP: beclomethasone equivalents; NA: not applicable; FEV1: post-bronchodilator forced expiratory volume in $1 \mathrm{~s} .{ }^{\#}$ : $p<0.01$, symptomatic versus paucisymptomatic. " : $p=0.02$, symptomatic versus paucisymptomatic. 
children with severe asthma, 24 were assigned to the S group, and 12 to the PS group. Children in both groups had similar general characteristics, except for the number of exacerbations in the past 12 months and the post-bronchodilator predicted FEV1\%.

\section{Mast cell distribution in asthmatic versus control subjects}

One value for ASM MCs, labelled by c-kit from a child in the asthmatic group, was greater than the 99th percentile and was excluded from the analysis. After staining with c-kit, the number of submucosal and ASM MCs did not differ between children with asthma and control subjects (figures 1 and 2, table 2). However, the number of MCs stained by Giemsa was higher in control subjects than in children with severe asthma $(\mathrm{p}=0.03)$. We found MCs in ASM bundles of 12 out of 36 children with severe asthma (33\%), whereas only two out of nine control subjects (22\%) had detectable MCs in the ASM.

Mast cell distribution in children with symptomatic versus paucisymptomatic severe asthma After staining with c-kit, the number of submucosal MCs in the S group (13.5 (2-23)) was higher than in the PS group (3 (0.5-5), p=0.02) (figure 3). We observed MCs labelled by c-kit in the ASM of 10 out of 24 patients from the S group (42\%), and 2 out of 12 patients from the PS group (17\%). The number of ASM MCs of two patients (one in each group) was greater than the 99th percentile and these values were excluded from the analysis. The number of ASM MCs tended to be higher in the S group (0 (0-4.5)) than in the PS group $(0(0-0), \mathrm{p}=0.06)$, although this was not significant. The number of MCs stained by Giemsa was similar between the two groups $(2(0-7)$ versus $0(0-4.8), \mathrm{p}=0.31)$.

Using two or more severe exacerbations as a cut-off value as recommended in the ATS/ERS guidelines gave similar results [21]. We found a higher number of submucosal MCs in the S group ( $\mathrm{n}=26)$ than in the PS group $(n=10, p=0.02)$ but no difference in the number of ASM MCs or MCs stained by Giemsa between the groups (details are available in the supplementary material).

\section{Correlation between mast cell numbers and asthma features}

Mast cells and clinical presentation

We first estimated the effect of ICS on the number of MCs in children with severe asthma, and found no correlation between the dose of ICS and the number of submucosal and ASM c-kit ${ }^{+}$cells $(\mathrm{p}=0.13$, $\mathrm{r}=-0.25$ and $\mathrm{p}=0.13, \mathrm{r}=-0.26$, respectively), or the number of MCs stained by Giemsa $(\mathrm{p}=0.07, \mathrm{r}=-0.31)$. The number of submucosal MCs stained by c-kit positively correlated with the number of severe exacerbations $(p=0.02, r=0.37)$, but not with the number of hospitalisations for asthma exacerbation $(\mathrm{p}=0.66, \mathrm{r}=0.07)$ (figure 4). We found no correlation between the number of ASM MCs and the number of severe exacerbations $(\mathrm{p}=0.09, \mathrm{r}=0.30)$, or the number of hospitalisations for asthma exacerbation $(\mathrm{p}=0.66, \mathrm{r}=-0.08)$. There was no correlation between the number of submucosal and ASM MCs and daily symptoms (not shown). We found no correlations between the number of MCs stained by Giemsa and the number of exacerbations, hospitalisations or daily asthma symptoms (not shown).

FIGURE 1 Mast cells stained with c-kit in the submucosa (red arrows) and airway smooth muscle (black arrow) of a child with severe asthma. Original magnification $\times 20$.

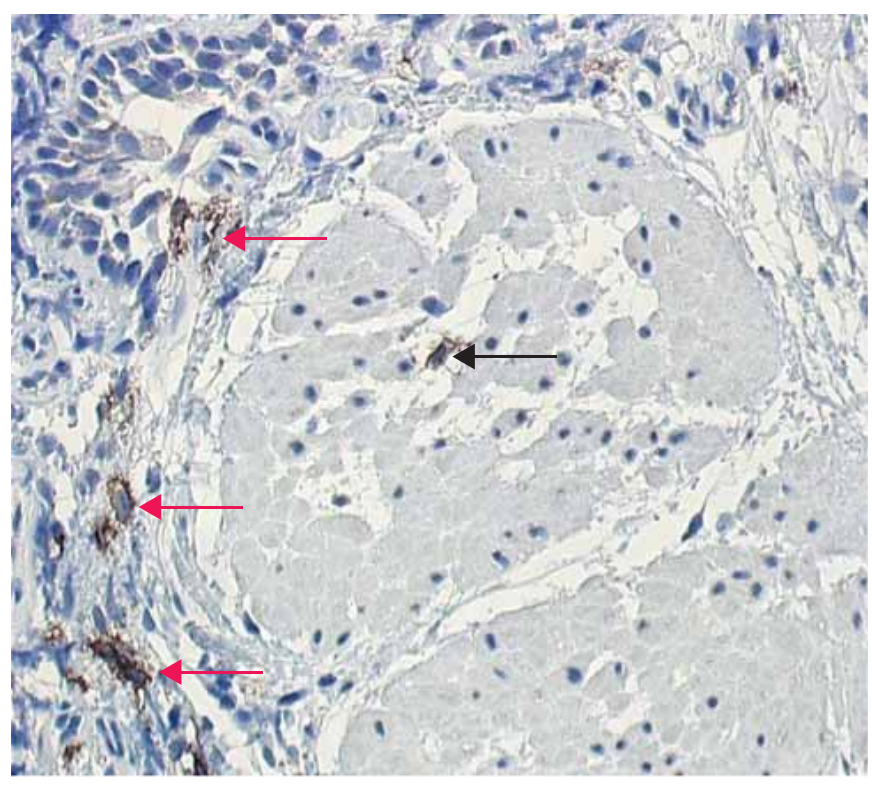



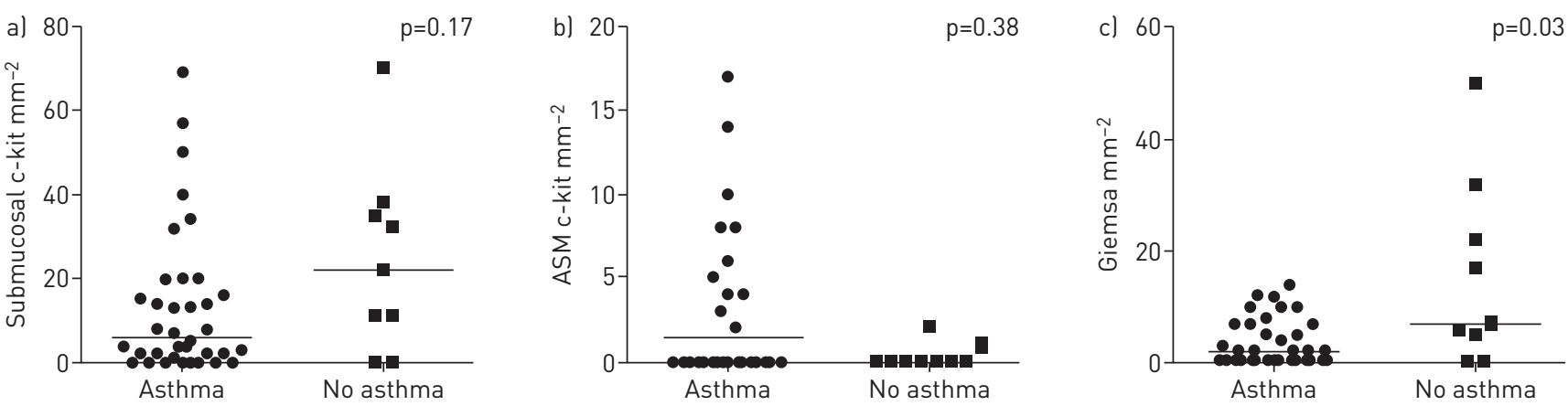

FIGURE 2 The numbers of a) submucosal mast cells (MCs) and b) MCs stained by c-kit in the airway smooth muscle (ASM) were similar between children with asthma and control subjects. c) The number of MCs stained by Giemsa was smaller in children with asthma than in the control group.

\section{Mast cells and airway inflammation}

Inflammatory cell numbers in BAL did not correlate with the number of MCs stained with c-kit or Giemsa (table 3).

The number of submucosal and ASM MCs labelled by c-kit, as well as the number of MCs stained with Giemsa, consistently correlated with the number of eosinophils in the submucosa (table 3, figure 5). No correlations were found between the number of MCs and other submucosal inflammatory cell types.

\section{Mast cells and markers of remodelling}

The number of submucosal and ASM MCs stained by c-kit and the number of MCs stained by Giemsa did not correlate with RBM thickness, the percentage of the submucosa occupied by mucus glands and ASM, the vessel numbers, or epithelial integrity (table 3 ).

\section{Mast cells and lung functions}

Neither the number of submucosal and ASM MCs stained by c-kit, nor the number of MCs stained by Giemsa correlated with post-bronchodilator predicted $\mathrm{FEV}_{1} \%$, FEV1/FVC or the predicted forced expiratory flow at $25-75 \%$ of $\mathrm{FVC}$ ( $\mathrm{FEF} 25-75 \%)$ (details are available in the supplementary material).

\section{Discussion}

We analysed whether the number of MCs was related to symptoms, lung function, inflammation and markers of remodelling in children with severe asthma. The number of MCs was rather lower in children with severe asthma than in control subjects. However, we found that the number of submucosal and ASM MCs was higher in children with frequent severe exacerbations than in those with few severe exacerbations. Accordingly, the number of submucosal MCs positively correlated with the number of severe exacerbations and eosinophilic infiltration in the submucosa. Finally, there was no relationship between the number of MCs and lung functions or airway remodelling.

The number of MCs in airways of people with asthma is highly variable between studies [4, 9, 24-26]. Differences in asthma phenotypes, severity and corticosteroid treatment could account for this variability. The method used to enumerate MCs could modify the results. Most asthma studies used antibodies against tryptase $[4,9,10,12,15-17]$ to identify MCs, whereas others used antibodies against c-kit [8, 27, 28]. Tryptase is trapped in intracytoplasmic granules. Thus degranulation of MCs, as observed in asthma $[2,8]$, could cause extracellular staining and misestimation of the number of MCs. c-kit antibodies bind to the transmembrane receptor c-kit, present on both degranulated and intact MCs, resulting in less confusion with extracellular staining and a lower risk of misestimating the number of MCs. We found that the

TABLE 2 Number of mast cells in asthmatic and control subjects

\begin{tabular}{|c|c|c|c|}
\hline & Asthma & No asthma & $p$ value \\
\hline Number of patients & 36 & 9 & \\
\hline SM c-kit $\mathrm{mm}^{-2}$ & $6(1.8-17)$ & $22(11-35)$ & 0.17 \\
\hline ASM c-kit mm ${ }^{-2}$ & $0(0-2.8)$ & $0(0-0)$ & 0.38 \\
\hline Giemsa mm m $^{-2}$ & $2(0-7)$ & $7(5-22)$ & 0.03 \\
\hline
\end{tabular}

Data are presented as median (interquartile range). SM: submucosal; ASM: airway smooth muscle. 

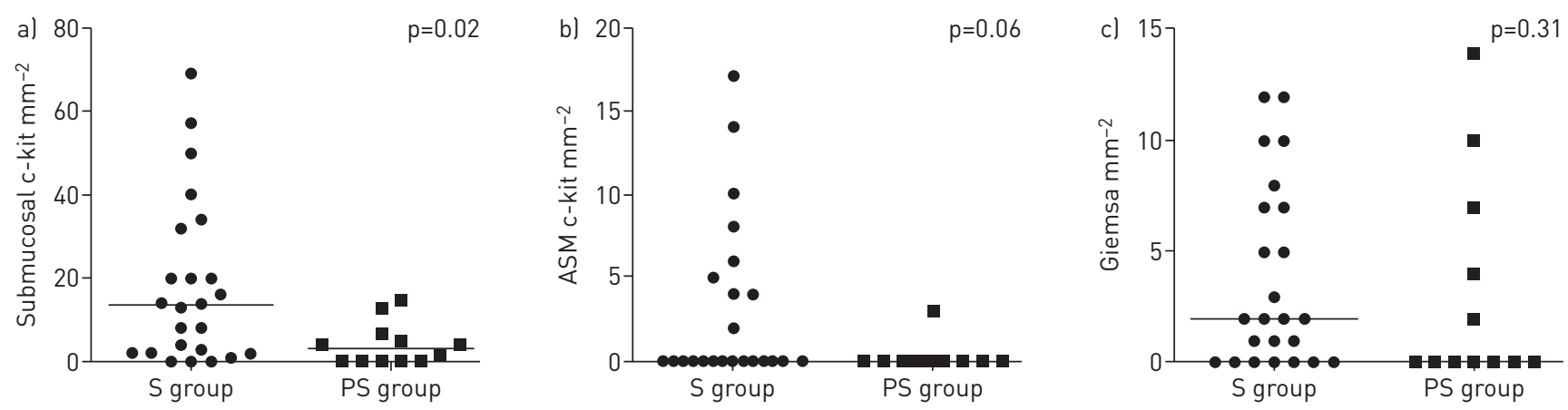

FIGURE 3 The numbers of a) submucosal mast cells (MCs) and b) airway smooth muscle (ASM) MCs stained by c-kit were greater in the symptomatic (S) group than in the paucisymptomatic (PS) group. c) There was no difference in the number of MCs stained by Giemsa between the two groups.

number of MCs detected using Giemsa was higher in control subjects than in children with severe asthma, whereas the number of MCs labelled by c-kit was similar. Giemsa stains the intracytoplasmic granules of MCs, reflecting the population of intact MCs. We can therefore speculate that more MCs were degranulated in the children with severe asthma than in control subjects.

Submucosal MC numbers were higher in children with frequent severe exacerbations regardless of the cut off for the number of severe exacerbations. We confirmed this finding when we treated the number of severe exacerbations as a continuous variable, showing a positive correlation between the number of submucosal MCs and the number of severe exacerbations. Consistent with this finding, the number of ASM MCs tended to be higher in the $\mathrm{S}$ group, and the absence of a correlation between the number of ASM MCs and severe exacerbations could be related to the small number of children with asthma who had MCs in their ASM. Oral steroids can reduce the number of MCs in the airways of people with asthma [26, 29]. However, an effect of oral steroids on the reduction of MCs in the PS group seems unlikely, because children in the $S$ group received six times more oral steroid bursts within the previous year than children in the PS group. Our results are consistent with the higher level of prostaglandin D2 (PGD2) - the main prostanoid produced by activated MCs - observed in BAL fluid from adults with asthma with recent exacerbations relative to those without exacerbations [30], as well as with the high MC degranulation rate observed early after the beginning of a fatal exacerbation in the ASM of adults [31]. Our results also reinforce the finding that the number of $\operatorname{IgE}^{+} \mathrm{MCs}$ is associated with the severity of exacerbations [11], and that the number of ASM MCs is related to poor asthma control in adults [32]. In children with asthma, exacerbations are often triggered by viral infections and allergen exposure, both factors that can trigger MC degranulation [33-35]. Thus, MCs might be directly involved in the pathogenesis of exacerbations. However, the correlation between MC numbers and severe exacerbations was weak and other factors could play a role in asthma exacerbations [36]. In this context, we found in a previous study that intraepithelial neutrophils and eosinophils were associated with frequent severe exacerbations in children with severe asthma [18].

Eosinophilic inflammation is one of the key features of severe asthma in children, but is still poorly understood [37]. Adults with severe asthma and eosinophilic infiltration have a higher number of submucosal MCs than those without eosinophilic infiltration [7]. In addition, in adults with asthma, eosinophilic inflammation positively correlates with the number of MCs that express IgE [11] and the number of c-kit ${ }^{+}$cells [28]. Our findings extend these results to children with severe asthma. Ongoing airway eosinophilic inflammation in

FIGURE 4 Positive correlation between the number of submucosal mast cells stained by c-kit and the number of severe exacerbations during the previous 12 months in children with severe asthma.

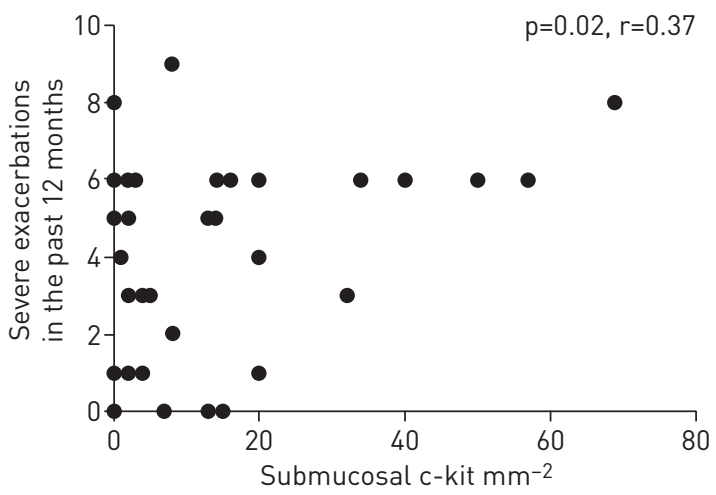


TABLE 3 Relationship between the number of mast cells and the number of inflammatory cells in bronchoalveolar lavage, in the submucosa, and with markers of remodelling in children with asthma

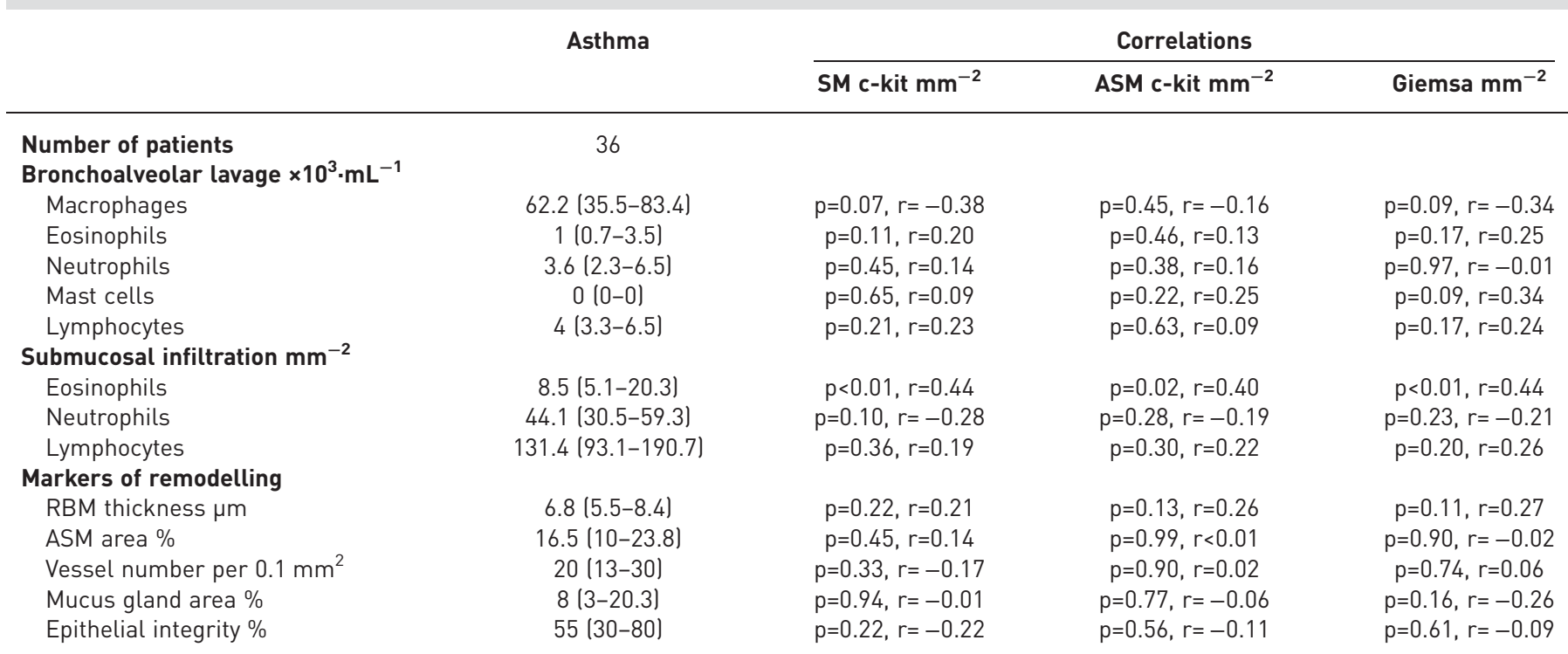

Data are presented as median (interquartile range), unless otherwise stated. SM: submucosal; ASM: airway smooth muscle; RBM: reticular basement membrane.

children with severe therapy-resistant asthma does not appear to be associated with increased expression of TH2 cytokines such as interleukin (IL)-4, IL-5 or IL-13 [17]. Thus, TH2-independent factors could drive persistent eosinophilia in these patients. In vitro findings have shown that MCs increase eosinophil survival through the secretion of granulocyte macrophage colony-stimulating factor, and that PGD2 and C-C chemokine receptor type 3 (CCR3)-specific chemokines can exert a chemotactic effect on eosinophils [38, 39]. The correlation we found between the numbers of MCs and eosinophils is consistent with these data, and raises the hypothesis that MCs could promote eosinophilia of the airways in children with severe asthma.

We found no relationship between MC number and lung function in children with asthma, as recently reported $[15,17,19,40]$. This could be due to the fact that, unlike adults, lung function in children with severe asthma is often normal and is a poor marker of asthma severity in this population. It might also be related to the heterogeneity of the patients addressed in our study. PS patients could represent a group of patients with asthma who share specific pathophysiological mechanisms. In addition, the status of MCs (degranulated/untouched cells) is probably more important than their number in the control of lung function and interactions with ASM.

Our study has several limitations. First, this is a cross-sectional study and symptoms were not assessed prospectively. However, all children with severe asthma underwent an assessment protocol of their condition.
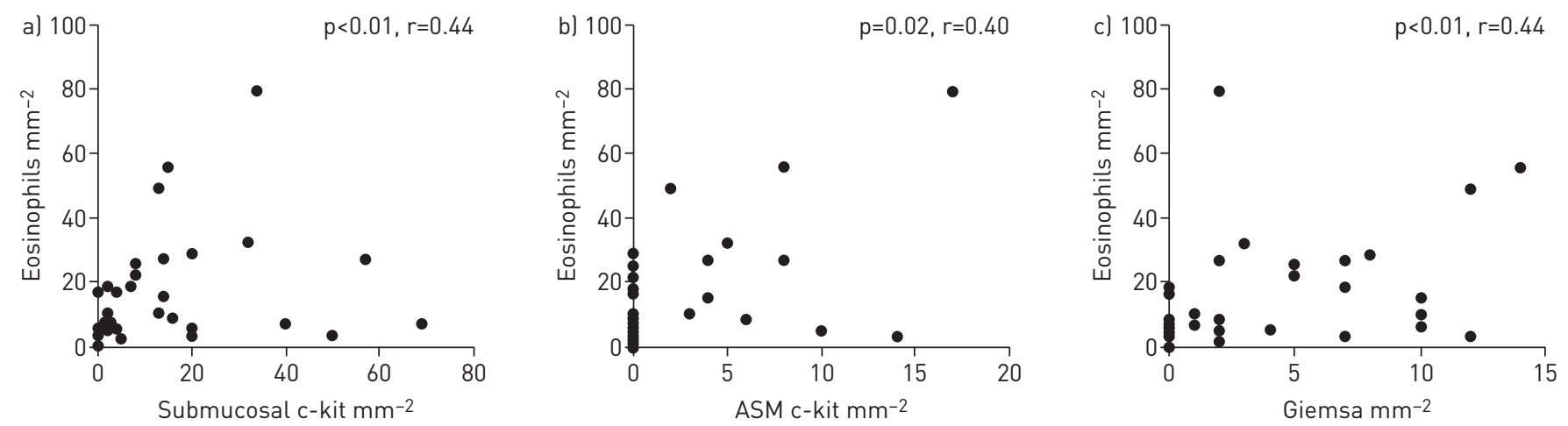

FIGURE 5 Positive correlations between the number of eosinophils in the submucosa and a) the number of submucosal mast cells (MCs) stained by c-kit, b) the number of airway smooth muscle (ASM) MCs stained by c-kit and c) the number of MCs stained by Giemsa in children with severe asthma. 
The distinction between S and PS children was based on clinical reports from the previous year, thus reliably reflecting the distinct phenotype of the asthmatic subjects. Second, all children with asthma were treated with high doses of inhaled steroids, which can potentially reduce MC numbers, even if it was shown that the number of MCs remains stable after a 16-week course of inhaled steroids [41]. The number of MCs could have been underestimated in children with asthma more than in control subjects owing to a higher frequency of degranulated cells in children with asthma. However, studies in children with milder asthma cannot be performed for ethical reasons. Studies including control subjects without airway disease would have led to a better determination of the specificity of MC myositis in children with asthma, but are not feasible for ethical reasons. The inclusion of children with eosinophilic bronchitis, a condition characterised by eosinophilic inflammation and airway remodelling but no variable airflow limitation or airway hyperresponsiveness $[9,10]$, would also have been useful, but this condition is rare in children. Finally, our data were obtained on a highly selected population, and cannot be extrapolated to children with milder symptoms.

In conclusion, this study shows that MCs are located in the submucosa and more specifically in the ASM in children with severe asthma. MC numbers are associated with clinical presentation and chronic eosinophilic inflammation, but not with remodelling or lung function. Our data support the involvement of MCs in both chronic airway inflammation and acute exacerbations. The development of therapies targeting MCs in the most symptomatic children with eosinophilic severe asthma could help to decrease airway inflammation and improve asthma symptoms.

\section{Acknowledgements}

The authors thank Professor Thierry Molina for his valuable advice, and Dr. Jean-Philippe Jais for his help in the statistical analysis.

\section{References}

1 Wang G, Baines KJ, Fu JJ, et al. Sputum mast cell subtypes relate to eosinophilia and corticosteroid response in asthma. Eur Respir J 2016; 47: 1123-1133.

2 Carroll NG, Mutavdzic S, James AL. Distribution and degranulation of airway mast cells in normal and asthmatic subjects. Eur Respir J 2002; 19: 879-885.

3 Balzar S, Chu HW, Strand M, et al. Relationship of small airway chymase-positive mast cells and lung function in severe asthma. Am J Respir Crit Care Med 2005; 171: 431-439.

4 Amin K, Janson C, Boman G, et al. The extracellular deposition of mast cell products is increased in hypertrophic airways smooth muscles in allergic asthma but not in nonallergic asthma. Allergy 2005; 60: 1241-1247.

5 Balzar S, Fajt ML, Comhair SAA, et al. Mast cell phenotype, location, and activation in severe asthma. Data from the Severe Asthma Research Program. Am J Respir Crit Care Med 2011; 183: 299-309.

6 Dougherty RH, Sidhu SS, Raman K, et al. Accumulation of intraepithelial mast cells with a unique protease phenotype in T(H)2-high asthma. J Allergy Clin Immunol 2010; 125: 1046-1053.

7 Wenzel SE, Schwartz LB, Langmack EL, et al. Evidence that severe asthma can be divided pathologically into two inflammatory subtypes with distinct physiologic and clinical characteristics. Am J Respir Crit Care Med 1999; 160: $1001-1008$

8 Begueret $\mathrm{H}$, Berger P, Vernejoux JM, et al. Inflammation of bronchial smooth muscle in allergic asthma. Thorax 2007; 62: 8-15.

9 Brightling CE, Bradding P, Symon FA, et al. Mast-cell infiltration of airway smooth muscle in asthma. $N$ Engl J Med 2002; 346: 1699-1705.

10 Siddiqui S, Mistry V, Doe C, et al. Airway hyperresponsiveness is dissociated from airway wall structural remodeling. J Allergy Clin Immunol 2008; 122: 335-341.

11 Balzar S, Strand M, Rhodes D, et al. IgE expression pattern in lung: relation to systemic IgE and asthma phenotypes. J Allergy Clin Immunol 2007; 119: 855-862.

12 Barbato A, Turato G, Baraldo S, et al. Epithelial damage and angiogenesis in the airways of children with asthma. Am J Respir Crit Care Med 2006; 174: 975-981.

13 Çokuğraş $\mathrm{H}$, Akçakaya N, Seçkin I, et al. Ultrastructural examination of bronchial biopsy specimens from children with moderate asthma. Thorax 2001; 56: 25-29.

14 Turato G, Barbato A, Baraldo S, et al. Nonatopic children with multitrigger wheezing have airway pathology comparable to atopic asthma. Am J Respir Crit Care Med 2008; 178: 476-482.

15 Baraldo S, Turato G, Bazzan E, et al. Noneosinophilic asthma in children: relation with airway remodeling. Eur Respir J 2011; 38: 575-583.

16 O'Reilly R, Ullmann N, Irving S, et al. Increased airway smooth muscle in preschool wheezers who have asthma at school age. J Allergy Clin Immunol 2013; 131: 1024-1032.

17 Bossley CJ, Fleming L, Gupta A, et al. Pediatric severe asthma is characterized by eosinophilia and remodeling without T(H)2 cytokines. J Allergy Clin Immunol 2012; 129: 974-982.

18 de Blic J, Tillie-Leblond I, Tonnel AB, et al. Difficult asthma in children: an analysis of airway inflammation. J Allergy Clin Immunol 2004; 113: 94-100.

19 Tillie-Leblond I, de Blic J, Jaubert F, et al. Airway remodeling is correlated with obstruction in children with severe asthma. Allergy 2008; 63: 533-541.

20 Proceedings of the ATS workshop on refractory asthma: current understanding, recommendations, and unanswered questions. American Thoracic Society. Am J Respir Crit Care Med 2000; 162: 2341-2351.

21 Chung KF, Wenzel SE, Brozek JL, et al. International ERS/ATS guidelines on definition, evaluation and treatment of severe asthma. Eur Respir J 2014; 43: 343-373.

22 Lødrup Carlsen KC, Hedlin G, Bush A, et al. Assessment of problematic severe asthma in children. Eur Respir J 2011; 37: 432-440. 
23 Lezmi G, Gosset P, Deschildre A, et al. Airway remodeling in preschool children with severe recurrent wheeze. Am J Respir Crit Care Med 2015; 192: 164-171.

24 Zanini A, Chetta A, Saetta M, et al. Chymase-positive mast cells play a role in the vascular component of airway remodeling in asthma. J Allergy Clin Immunol 2007; 120: 329-333.

25 Liesker JJ, Ten Hacken NH, Rutgers SR, et al. Mast cell numbers in airway smooth muscle and PC20AMP in asthma and COPD. Respir Med 2007; 101: 882-887.

26 Bentley AM, Hamid Q, Robinson DS, et al. Prednisolone treatment in asthma. Reduction in the numbers of eosinophils, T cells, tryptase-only positive mast cells, and modulation of IL-4, IL-5, and interferon-gamma cytokine gene expression within the bronchial mucosa. Am J Respir Crit Care Med 1996; 153: 551-556.

27 Fuehrer NE, Marchevsky AM, Jagirdar J. Presence of c-KIT-positive mast cells in obliterative bronchiolitis from diverse causes. Arch Pathol Lab Med 2009; 133: 1420-1425.

28 Al-Muhsen SZ, Shablovsky G, Olivenstein R, et al. The expression of stem cell factor and c-kit receptor in human asthmatic airways. Clin Exp Allergy 2004; 34: 911-916.

29 Djukanović R, Homeyard S, Gratziou C, et al. The effect of treatment with oral corticosteroids on asthma symptoms and airway inflammation. Am J Respir Crit Care Med 1997; 155: 826-832.

30 Fajt ML, Gelhaus SL, Freeman B, et al. Prostaglandin $\mathrm{D}_{2}$ pathway upregulation: relation to asthma severity, control, and TH2 inflammation. J Allergy Clin Immunol 2013; 131: 1504-1512.

31 Elliot JG, Abramson MJ, Drummer OH, et al. Time to death and mast cell degranulation in fatal asthma. Respirology 2009; 14: 808-813.

32 Saha SK, Berry MA, Parker D, et al. Increased sputum and bronchial biopsy IL-13 expression in severe asthma. J Allergy Clin Immunol 2008; 121: 685-691.

33 Galli SJ, Tsai M. IgE and mast cells in allergic disease. Nat Med 2012; 18: 693-704.

34 Shirato K, Taguchi F. Mast cell degranulation is induced by A549 airway epithelial cell infected with respiratory syncytial virus. Virology 2009; 386: 88-93.

35 Kulka M, Alexopoulou L, Flavell RA, et al. Activation of mast cells by double-stranded RNA: evidence for activation through Toll-like receptor 3. J Allergy Clin Immunol 2004; 114: 174-182.

36 Tillie-Leblond I, Montani D, Crestani B, et al. Relation between inflammation and symptoms in asthma. Allergy 2009; 64: 354-367.

37 Saglani S, Lloyd CM. Eosinophils in the pathogenesis of paediatric severe asthma. Curr Opin Allergy Clin Immunol 2014; 14: 143-148.

38 Elishmereni M, Alenius HT, Bradding P, et al. Physical interactions between mast cells and eosinophils: a novel mechanism enhancing eosinophil survival in vitro. Allergy 2011; 66: 376-385.

39 Pettipher R, Hansel TT, Armer R. Antagonism of the prostaglandin D2 receptors DP1 and CRTH2 as an approach to treat allergic diseases. Nat Rev Drug Discov 2007; 6: 313-325.

40 Barbato A, Turato G, Baraldo S, et al. Airway inflammation in childhood asthma. Am J Respir Crit Care Med 2003; 168: 798-803.

41 Kraft M, Martin RJ, Lazarus SG, et al. Airway tissue mast cells in persistent asthma. Predictor of treatment failure when patients discontinue inhaled corticosteroids. Chest 2003; 124: 42-50. 